\title{
Revistas mexicanas decimonónicas en la América poética
}

\author{
María Guadalupe Correa Chiarotti \\ Universidad Nacional Autónoma de México \\ lupecorrea@gmail.com
}

\begin{abstract}
RESUMEN: El artículo examina la incorporación de autores mexicanos en la América poética (1846), antología compilada por Juan María Gutiérrez. El trabajo estudia un hecho paradójico: México es uno de los países con mayor representación pese a los débiles vínculos que sus intelectuales establecen con sus pares sudamericanos y la dificultosa circulación de materiales. El análisis de los autores y poemas mexicanos y las obras de donde son extractados permite, a su vez, reflexionar acerca de la relación entre las revistas decimonónicas y las ideas de la generación del 37.
\end{abstract}

ABSTRACT: This article examines the incorporation of Mexican writers into the anthology América poética (1846), compiled by Juan María Gutiérrez. The paper studies a paradox: México is one of the most represented countries in spite of the weak connection that its intellectuals have with their South American peers and the poor circulation of poems. The analysis of Mexican poets, their work and the publications from which they are extracted, gives way in turn to an analysis of the relationship between nineteenth-century journals and the ideas of the generation of ' 37 .

Palabras Clave: América poética, Juan María Gutiérrez, publicaciones periódicas decimonónicas, generación del 37.

KeYwords: América poética, Juan María Gutiérrez, nineteenth-century journals, the generation of '37.

A lo largo de todo el siglo XIX abundan las obras literarias incitadas por la búsqueda y promoción de la originalidad del continente; en el terreno lírico, la América poética del argentino Juan María Gutiérrez (18091878) se erige como una de las más genuinas expresiones de esta tradición americanista. No por mero azar — tal como ha señalado Pedro Henríquez Ureña (273) - este vasto florilegio inicia su largo periplo con la "Alocución a la Poesía" (Londres, 1823) de Andrés Bello, considerada el acta de nacimiento del americanismo literario.

La América poética. Colección escogida de composiciones en verso... se publica por entregas en Valparaíso entre los años 1846-1847 y cuenta 
entre sus méritos ser el primer compendio de poesía hispanoamericana. De la reunión de estos fascículos resulta un tomo grueso (823 pp.) en $4^{\text {to }}$ mayor, encuadernado a la holandesa, de factura lujosa y cuidados todos sus aspectos de publicación - a cargo del editor Santos Tornero (cuyas siglas aparecen en la portada)—. La colección es introducida por unas palabras de "Los editores", sin firmas, aunque existen pruebas suficientes para afirmar que pertenecen a Juan María Gutiérrez, nombre que, en un exceso de cuidados, no aparece ni aquí ni en la portada ni en ningún otro espacio destinado a los créditos. Este exordio reproduce, por otra parte, el "Prospecto" que antecedió al lanzamiento de la obra, mismo donde se explican sus características y se invita al público a suscribir a la empresa. Con salvedad, como quedó dicho, del poema de Bello que abre la colección, los demás son dispuestos a dos columnas bajo el nombre de su autor o autora, colocados estos a su vez por orden alfabético (contrapuesto al acomodo por naciones que elegirán otras antologías). La semblanza de cada vate está formada con las noticias biográficas que llegan al compilador, quien incorpora algunos juicios críticos propios junto a los que halla desperdigados en libros y revistas periódicas misceláneas.

Con el claro designio de trazar una nueva cartografía poética de un territorio hondamente conmovido por las revoluciones políticas, reúne en sus páginas a más de cincuenta poetas de once países. ${ }^{1}$ Gertrudis Gómez de Avellaneda, Andrés Bello, Esteban Echeverría, Francisco Acuña de Figueroa, Rafael García Goyena, José María Heredia, Bartolomé Hidalgo, Juan Crisóstomo Lafinur, José Fernández Madrid, José Mármol, José Joaquín de Olmedo, los hermanos Florencio y Juan Cruz Varela, son algunos de los nombres que integran el índice. Dentro de este programa destaca el lugar privilegiado que ocupa México, en tanto es la nación que cuenta con mayor número de escritores (once) después de Argentina con quince. Entre los mexicanos, la nómina no desmerece: Alejandro Arango, Fernando Calderón, Manuel Carpio, José Bernardo Couto, José María Lafragua, Joaquín M. de Castillo y Lanzas, Manuel

${ }^{1}$ Al final del volumen, más específicamente bajo el índice, el mismo editor apunta: "La AMÉricA POÉTICA se ha publicado en 13 entregas. Apareció la primera en el mes de febrero de 1846 y la última a fines de junio de 1847. Comprende 53 autores; 455 composiciones escogidas de estos_ y más de 54,500 versos" (Gutiérrez 1846: 823). Tanto en esta cita como en todas las que siguen actualizamos la ortografía y deshacemos las abreviaturas. En notas reemplazamos Juan María Gutiérrez con la sigla JMG. 
Navarrete, José Joaquín Pesado, Guillermo Prieto, Andrés Quintana Roo y Francisco M. Sánchez de Tagle. Una suposición válida es que tal prioridad conlleva la estricta transferencia de la situación cultural mexicana y que este país se presenta a los ojos del antologador como un prolífero manantial poético. Pero aun si pudiéramos comprobar a través de un conteo de publicaciones o de un relevo de concursos que en ese punto geográfico la producción literaria fue prolífica, difícil sería omitir el empeño del propio Gutiérrez: la amplia participación mexicana se declara expresión de una voluntad integradora, del resuelto propósito de "demostrar y producir unidad" (Campra: 40).

De los múltiples aspectos ofrecidos al análisis por esta colección, nos interesa aquí indagar la génesis del proyecto, atendiendo de modo más puntual los mecanismos a partir de los cuales se obtiene el material de base. Pero ¿por qué detenerse en la coyuntura mexicana? Porque el escenario es diferente y más problemático al que se presenta en los demás bloques nacionales. Del ámbito rioplatense, por mencionar un ejemplo antagónico, Gutiérrez consigue el grueso de los poemas de primera mano, incluso apelando al envío ex profeso de composiciones por parte de los propios autores. ${ }^{2}$ Por el contrario, ningún vínculo de esta naturaleza se registra en territorio mexicano. Con las obras provenientes del norte, el encuentro se complejiza y se da de modo indirecto, principalmente a partir de publicaciones periódicas.

\section{GÉNESIS Y ANTECEDENTES}

Juan María Gutiérrez nace en Buenos Aires, meses previos a la Revolución de Mayo de 1810, donde las efemérides continentales marcan el

\footnotetext{
${ }^{2}$ Este pedido por parte de Gutiérrez puede corroborarse en las respuestas de Juan Carlos Gómez y Félix Frías. Dice el primero: "La promesa de usted es ya un placer para mí; en su realización tendré motivo de enorgullecerme. Siento tan solo no poder retribuir esa deuda sino con mi gratitud; sin embargo si algún día escribo algo bueno por su objeto, aunque por su forma sea malo, ese algo llegará hasta usted en cualquier punto donde se encuentre" (Gutiérrez 1979: 284, carta n 272, 4/9/1844, de Juan Carlos Gómez, Río Pardo, a JMG). A este cortés aplazamiento (Gómez integra la nómina final), Frías opone una negativa tajante: "Conozco por otra parte que lo que yo escribo en pobrísimo estilo no merece vivir sino a la rústica" (Gutiérrez 1979: 298, carta n² 288, 5/6/1845, de Félix Frías, Santiago de Chile, a JMG, Valparaíso).
} 
inicio de la independencia del Río de la Plata y de casi todas las regiones dominadas por el imperio español. Es, por tanto, hijo del movimiento emancipatorio y fervoroso adherente de la causa libertaria. La generación a la que pertenece, presidida por el poeta-ideólogo romántico Esteban Echeverría, se autoproclama heredera y defensora de los postulados de Mayo y, en tanto tal, juzga su deber sentar las bases, echar los cimientos - metáfora cara a los escritores del período- del edificio social, en todos y cada uno de los aspectos que lo componen.

Al menos dos nombres ha utilizado la crítica para referirse al grupo. El primero de ellos y el más generalizado es el de generación del 37, por ser justamente en 1837 cuando se inaugura el mítico Salón literario de Buenos Aires (homologable, en más de un sentido, a la Academia de Letrán), promovido por Marcos Sastre y en el que participan activamente Echeverría, Gutiérrez y Juan Bautista Alberdi. El Salón propicia el inicio de una larga y profunda reflexión en torno a la literatura nacional; pero no solo ella, sino que extiende su objeto a la realidad en su conjunto, a todo el vasto espectro de inquietudes que conforman la vida pública y la sociabilidad en su alcance más amplio. La vida del Salón es breve (no así su influjo): transcurridos apenas seis meses, Juan Manuel de Rosas - caudillo argentino por antonomasia - ordena su clausura. Desde entonces, sus miembros cruzan uno a uno la anchura del Río de la Plata para llegar a Montevideo e iniciar en la capital uruguaya un largo y penoso exilio. En esta circunstancia hace foco la otra denominación preferida por los historiadores de la literatura, la de generación de los proscriptos.

Son muchos los pensamientos, muchas las obras y aún más las iniciativas de esta "provincia semoviente". Ciñéndome al tema que nos ocupa, solo agregaré a estos párrafos preliminares que hacia 1842 ya está bosquejada la estructura fundamental de la Colección de poetas del Río de la Plata, antecedente regional y proyecto hermano de la América poética. Esta recopilación resulta de la sociedad de los uruguayos Andrés Lanas y Teodoro Vilardebó con los argentinos José Rivera Indarte y Juan María Gutiérrez, quienes se propusieron formar una colección lírica, antecedida — según rememora Bartolomé Mitre- por una historia de la poesía americana y coronada con un apéndice de notas críticas, biográficas, históricas, geográficas y científicas (cfr. Rocca: XxxI). Esta obra corrió una suerte azarosa: desperdigados sus autores, atravesada por bloqueos y sitios, archivada y olvidada luego, permaneció 
inédita por más de 160 años. Pablo Rocca, responsable de este rescate bibliográfico, da a conocer en 2011 en un mismo volumen los dos textos sobrevivientes:

un manuscrito inconcluso de la recopilación poética y un conjunto orgánico, dependiente de esta y también inacabado, que lleva por título Notas para la colección de Poetas del Río de la Plata que compilaban en Montevideo en 1842 los Sres D. Juan $M^{a}$. Gutiérrez, D. José Rivera Indarte y D. Andrés Lamas [renombrado Vocabulario] (xxxII).

En 1843 Gutiérrez se embarca junto a Alberdi rumbo a Europa, dejando atrás Uruguay y el inacabado volumen rioplatense. Ya de regreso en América, Gutiérrez pasa a Brasil, más específicamente al estado de Rio Grande do Sul, donde transcurren los días de "vida vegetativa y puro destierro", hecho que lo impulsa a emprender un nuevo traslado, ahora hacia las costas del Pacífico.

\section{AMPLIACIÓN AMERICANISTA}

El epistolario de Gutiérrez constituye una fuente documental indispensable a la hora de rastrear la gestación de la América poética. El primer asomo de esta idea data de agosto de 1844, en una carta dirigida a Esteban Echeverría:

Si puedo juntarme con Juan Antonio [hermano de Juan María residente en Guayaquil] y este se halla, como presumo, en buen estado de medios, es probable que pase a donde pueda hacer la publicación que tanto deseo de poesías del Río de la Plata. Tengo a este fin muchos materiales y no me aparto de ellos (Gutiérrez 1979: 283). ${ }^{3}$

De esta breve cita se desprenden algunos argumentos que conviene destacar. Por una parte, revela que el plan editorial de Gutiérrez determina su movilidad y condiciona su futuro asiento a las posibilidades efectivas de publicación. Así, la América poética no solo constituye un producto de los desterrados argentinos, sino que también influye en buena medida en el arribo del joven poeta a Valparaíso. Por otra parte,

\footnotetext{
${ }^{3} \operatorname{Carta~}^{\circ}$ 271, 7/8/1844, de JMG, Porto Alegre, a Esteban Echeverría, Montevideo.
} 
las palabras extractadas dejan ver que persiste en su idea de dar a conocer la colección ceñida, todavía, al territorio acotado por el Río de la Plata.

¿Qué lo lleva a ensanchar su objeto?, ¿por qué la antología se torna luego "americana"? Resulta incierta la resolución de estos interrogantes; hecho que no nos impide, sin embargo, aventurar ciertos elementos capaces de influir en la expansión del propósito originario.

Un primer supuesto se eslabona con la variación en la óptica de sus compañeros de exilio, quienes extienden sus intereses al ámbito americano en su conjunto. Por estos años, Alberdi y Echeverría -interlocutores principales de Gutiérrez- conciben proyectos de amplio alcance: en tanto Alberdi prepara las entregas que agrupa bajo el título de Politica continental (1844), Echeverría trabaja en la "Ojeada retrospectiva..." (1846) y en su Manual de enseñanza..., ${ }^{4}$ escritos donde fácilmente se percibe la amplificación del objeto. Tanto es así que, refiriéndose a este último título, Echeverría no duda en enfatizar la correspondencia entre los países y, por lo tanto, el carácter extensivo de su Manual: "Mi obra no es local sino americana, porque es uno el espíritu y la tendencia de la revolución de los pueblos sudamericanos" (Gutiérrez 1979: 290). ${ }^{5}$

Por lo demás, resulta sugerente asociar la expansión de la antología con el traslado de Gutiérrez a Chile, donde se instala en 1845. De los "cuyanos" (mote con que se conocía a los argentinos), dice Ricardo Rojas:

De entre los argentinos que vivieron en Chile, cinco se destacan igualmente gloriosos en la cultura de aquel país y del nuestro: Sarmiento, Alberdi, Gutiérrez, López, Mitre, entonces jóvenes periodistas "chilenos", y después maestros de civilización en toda América. Cuando regresaron a su país, el primero y el último fueron presidentes de la república; los otros tres pudieron haberlo sido (Rojas: 178).

${ }^{4}$ El Dogma se había publicado por primera vez en 1839, con el nombre de Código o declaración de los principios que constituyen la creencia social de la República Argentina (Montevideo: Iniciador). En 1846, Echeverría publica la segunda edición (Montevideo: Imprenta del Nacional), precedida por la "Ojeada retrospectiva sobre el movimiento intelectual en el Plata desde 1837". El mismo año da a conocer su Manual de enseñanza moral para las escuelas primarias del Estado oriental.

5 Carta n² 279, 24/12/1844, de Esteban Echeverría, Montevideo, a JMG. 
Esta nota sirve a los fines de enfatizar la potencia y el vigor intelectual del colectivo al que pertenece Gutiérrez, pero también para constatar el calibre de sus intereses políticos y la pugna librada en el ámbito argentino por la hegemonía de sus proyectos de nación. Con todo, estos jóvenes no conforman un grupo aislado y, movidos por un afán permanente de intervenir en la realidad, de producir materiales útiles y ensayar ideas novedosas, no tardan en entrar en contacto con los demás letrados sudamericanos reunidos especialmente en Santiago (cfr. Stuven 2008). Muestra de estos nuevos vínculos es la relación que Gutiérrez entabla con Andrés Bello, quien no solo ostenta una obra de difícil exclusión en un florilegio de este tipo —alargando los límites hasta Venezuela-, sino que, además, él mismo se presta como colaborador y pone a prueba la estrechez rioplatense al sugerir la presencia de José María Heredia y José Fernández Madrid —cubano y colombiano respectivamente-.${ }^{6}$ Se sella así la suerte de la obra: una antología de índole continental.

A partir de entonces, interesado en procurar tanto las poesías de los autores escogidos y sus noticias biográficas como la divulgación del proyecto, Gutiérrez apela a todo tipo de artimańas. Para ello moviliza a un nutrido séquito de colaboradores a fin de que examinen periódicos o colecciones en bibliotecas — públicas y privadas-; a otros encomienda dar a conocer entre sus pares y en medios propagandísticos los fascículos de inminente aparición; a muchos — como se anticipó- solicita el envío de lo más selecto de sus obras. Todo ello a la vez que publica el "Prospecto", donde se fija la intención del plan y el mecanismo de suscripción. ${ }^{7}$ Los mismos poetas son quienes con mayor ahínco soco-

${ }^{6}$ Por intermedio de Rafael Minvielle llega a Gutiérrez la siguiente información: "me ha dicho [Bello] que en las poesías de Heredia hay cosas bastante buenas; me dio un tomo de las de Fernández Madrid, que yo le mandaré en ocasión oportuna. Dice que en El Mercurio encontrará usted muchas buenas poesías; que no quisiera que se publicase nada suyo porque no hace mucho que leyó un poema sobre la América y le causó fastidio; que en caso que usted no ceda y publique algo de él, como todos saben que A. B. es Andrés Bello, vale más ponerlo todo" (Gutiérrez 1979: 297, carta n 287, s/f, de Rafael Minvielle, Santiago de Chile, a JMG, Valparaíso). Palabras mediadas donde, con método barroco, Bello se excusa de participar, no por desalińo del verso (como interpondrán otros), sino por "fastidio". Gutiérrez, con todo, desoye el consejo o, mejor, lee perfectamente el mensaje cifrado en el más puro estilo cortesano.

7 Este "Prospecto" habría aparecido por primera vez en El Mercurio de Valparaíso en septiembre de 1845. Sarmiento introdujo y presentó el escrito de Gutiérrez en 
rren las actividades de Gutiérrez, tanto más cuanto que, los que están enterados, no permanecen pasivos ante la posibilidad de integrar este novísimo parnaso americano. Domingo Faustino Sarmiento, con su punzante malicia, así lo expresa:

Me dijo [Montt] con una seriedad imperturbable que un poeta (Chacón) había ido ex profeso a Valparaíso a solicitar de usted que lo admitiese en el areópago de los poetas americanos. Yo le insinué que el amor propio de cada tonto que haya desbastado palabras para hacer cosas de versos, sería el más activo colaborador que usted tendría en su obra; que a la primera entrega que hiciese circular por América, no quedaría poetastro ramplón que no exclamase: “¡Y yo! ¿Cómo mis versos no están aquí?, sobre todo mi composición a la Petrona o a la Pepa, mi despedida, mi... Ya, no habrá llegado a noticia del colector" y un fardo de malos versos vendrá de cada sección americana (Gutiérrez 1981: 19). ${ }^{8}$

Las predicciones de Sarmiento fueron, con todo, bastante ciertas. Y ante el fárrago poético proveniente de diversos puntos de la América hispánica, el silencio epistolar de los mexicanos es notorio: ni una carta se registra en el archivo de Gutiérrez datada en México por estos años. ${ }^{9}$ Asimismo, tampoco se advierte la presencia de colaboradores mexicanos, ni publicidad en la prensa del prospecto y, por lo mismo, del lanzamiento de los fascículos.

el Progreso el 9 de septiembre de 1845 (cfr. Sarmiento: 317-319. También las cartas $\mathrm{n}^{\circ} 307 / 308$ de Sarmiento y Alberdi respectivamente en Gutiérrez 1981). Rodríguez Marín (2005/6) consigna una reimpresión: "América Poética. O sea Coleccion escojida de composiciones en verso escritas por Americanos en el presente siglo. Prospecto" (Comercio del Plata no 32, 8/11/45).

${ }^{8}$ Carta $^{\circ} 307,9 / 10 / 1845$, de Domingo Faustino Sarmiento, Santiago de Chile, a JMG, Valparaíso.

9 Solo localizamos una nota de autor desconocido que Gutiérrez recibió en París ańos antes (1843). En este enigmático memorándum se pasa revista de los nombres más célebres con que cuenta México en el campo de la literatura, el derecho y la política y de los principales héroes de la independencia. Este índice puede corresponder a la pluma de José María Luis Mora (residente en París por esos años), aunque todavía no encontramos ningún dato que corrobore tal hipótesis. Cfr. Gutiérrez 1979: 255256, carta ${ }^{\circ} 248,7 / 10 / 1843$, de París, a JMG, París, Memorándum sin firma. 


\section{EL CASO MEXICANO}

La posición marginal de México con respecto a los países del sur —al menos en cuanto a contacto literario se refiere - imposibilita la participación directa de sus letrados en la antología. Sin asedio de poetas reclamando ser admitidos, pero también sin auxilio, no queda más remedio que recurrir a los impresos que Gutiérrez tiene a la mano. Las fuentes que utiliza son más acertadas que variadas, lo que nos coloca frente a un parco repertorio: tan solo tres libros de autor, los Ocios juveniles de Joaquín M. de Castillo y Lanzas, los Entretenimientos poéticos de Manuel Navarrete y las Poesías originales y traducidas de José Joaquín Pesado; una antología, la Colección de poesías mejicanas de José María Luis Mora, y tres publicaciones periódicas. ${ }^{10}$ De este conjunto se extrae el $20 \%$ de los autores que integran el índice y casi 140 páginas (representan cerca del $17 \%$ del total). Números que, insistimos, no hallan correlato con la disponibilidad bibliográfica y donde se hace visible el empeño de integrar a las Américas.

Permítaseme hacer un alto en este punto para referir brevemente la convulsa situación que vive México en los años cuarenta, la cual encuentra resonancia, sin duda, en el opaco desarrollo de la industria editorial y la difícil circulación de revistas por el resto del continente, no obstante lo cual, pervive el vínculo.

Si es cierto que hacia 1846, cuando comienza la publicación de la América poética, Valparaíso se afirma como un activo puerto comercial, con una vida cultural bullente y contagiado del clima de prosperidad chileno, si resulta de ello un medio propicio, un marco oportuno para el engrandecimiento de las ideas, la apertura continental y la vindicación del proyecto bolivariano, no lo es menos que la disposición de las cosas en México dista, por mucho, de ser equiparable. Son, según opinión ampliamente compartida, los más tristes años de la historia mexicana. Aun con lo que tienen de caóticas e intestinas las luchas en el sur del continente, ninguna nación padece de modo tan vívido la inminencia del desmembramiento como México.

${ }^{10}$ Joaquín M. de Castillo y Lanzas. Ocios juveniles. Filadelfia: Imprenta de E. G. Dorsey, 1835; Manuel Navarrete. Entretenimientos poéticos. Primera edición. México: 1823; José Joaquín Pesado. Poesías orijinales y traducidas. México: 1839; José María Luis Mora. Colección de poesías mejicanas. París: Librería de Rosa, 1836. Dudamos del conocimiento que pudiera tener Gutiérrez de la autoría de esta última colección. 
La Constitución española de 1812 dispone bajo el nombre de América septentrional un territorio que desde California, Nuevo México y Texas hasta la Capitanía de Guatemala conforma una inmensa, compleja y rica estructura administrativa. Guatemala se separa poco antes de la jura de la Constitución de 1824; en ese momento "el federalismo hizo el milagro de mantener la integridad territorial y permitió que Chiapas se incorporara a México en octubre de 1824" (Serrano Ortega; Vázquez: 407). A partir de allí se encarnizó la pugna interna entre los defensores del centralismo y los adeptos al federalismo (además, ciertamente, de los promotores de la monarquía). Unos y otros se alternan el mando, aunque ambos sin alcanzar brillo:

el centralismo fracasó por las mismas razones que el federalismo: falta de recursos y de coordinación territorial, incapacidad para defender y controlar un extenso territorio casi deshabitado, expuesto al contrabando y al expansionismo, y la resistencia de las élites regionales (425).

Durante 1843 y 1844 destacan la separación de Yucatán, las amenazas de Texas, las difíciles negociaciones en el Congreso y las constantes revueltas contra la capitación (impuesto de un real mensual a todo varón de entre 16 y 60 años de edad). La desarticulación y la falta de acuerdo hacen que el ejercicio de mando sea poco más que ideal; la violencia y la ruina económica sumen al país en un estado de indefinición y desorden generalizado: hacia 1845, mismo año en que se publica el "Prospecto", aquejan al país las intrigas internas y las amenazas externas. La prosecución de este paralelo cronológico resulta bastante elocuente: mientras en Valparaíso se imprimen los ejemplares del primer fascículo de la América poética (febrero de 1846), las tropas estadounidenses avanzan del Río Nueces (frontera de Texas y Coahuila) al Río Grande, lo que implica una afrenta, una invasión al territorio mexicano y, con ella, la respuesta que sirve de excusa para que el presidente James Polk declare la guerra a México. En junio de 1847 se publica la última entrega del volumen, con la cual se completa la antología; poco después, el 15 de septiembre, la bandera norteamericana ondea en el Palacio Nacional de México.

En este contexto, la ausencia de colaboración mexicana se sobrentiende. Si uno de los rasgos que define el espíritu del tiempo en términos continentales es el ser esta una época eminentemente "política", el 
atributo se convierte en la nota distintiva de México durante los ańos que nos ocupan. Con estos precedentes, es dable comprender, por un lado, el poco trato con los intelectuales del sur del continente (hecho que, de todos modos, persiste en condiciones más favorables), ensimismados como estaban los letrados mexicanos en los asuntos de Estado y ocupados en dar publicidad a sus ideas en la prensa local; y, por el otro, que Gutiérrez acuda a revistas - y no tanto a libros- a la hora de diversificar la nómina de autores mexicanos y colectar material que redunde en pluralidad y representación, imperativos de una antología hispanoamericana que se precia, como esta, de ser moderna e íntegra.

En este sentido, con respecto a la escasa factura de libros mexicanos y las dificultades que los autores hallan a la hora de imprimir, apunta Fernando Tola:

En fin: lo elemental radica en el alto costo de editar un libro y en la necesidad de que fuera el autor, o algún mecenas que lo apoyara, quien debía pagar las facturas de tipografía, papel, impresión y encuadernación. Este aspecto económico, obligaba, en consecuencia, a reducir los tirajes y a tratar de lograr cierto número de suscriptores que garantizaran la venta de los ejemplares necesarios para cubrir el costo de edición (Tola de Habich: Cxxi).

A este pasaje añade Marco Antonio Campos una oportuna consideración: "no solo era una aventura editar un libro, sino era dramática la falta de lecturas en un país con una altísima tasa de analfabetismo" (594). A partir de ciertos pormenores en torno a la empresa que Ignacio Cumplido prepara hacia 1844, el Parnaso Mexicano, Fernando Tola infiere que los escritores mexicanos "tampoco estaban interesados en editar en libro sus escritos", supone "que vivieron sepultados por la presión del periodismo, y en especial del periodismo cultural, y ellos mismos menospreciaron sus escritos": "se pasaban el santo día escribiendo sin pensar jamás en reunir textos para publicar un libro" (CXXIII-V). ${ }^{11}$

11 "Cuenta mucho para la falta de memoria literaria que en el siglo XIx los autores escribieran profusamente... pero en periódicos y revistas", agrega Campos (593) y hace a continuación un recuento de las obras publicadas por los escritores de la Academia de Letrán, del que copio aquellas que interesan a la América poética: hacia 1839 José Joaquín Pesado, con 38 años, reúne sus poemas que reaparecerán aumentados en una nueva edición en 1849 (y reeditados póstumos en 1855 y 1886); Manuel Carpio "no 
En estas circunstancias, el auxilio de las publicaciones periódicas en el bloque mexicano es sustancial.

Para compensar esta merma, las tres revistas que prestan composiciones son El Apuntador, El Museo Mexicano y El Recreo de las Familias. ${ }^{12}$ Las dos últimas destacan del cúmulo de lo que dio en llamarse "revistas literarias", las cuales proliferaron a partir de la cuarta década del siglo XIX (Suárez de la Torre: 14-15), por lo que estarían, en cierto modo, más cercanas al objeto de la América poética. La primera, El Apuntador, pertenece a otro ámbito — vecino quizá, pero otro—: es una "revista especializada", una "publicación artística dedicada a dar noticia de los trabajos teatrales, criticar las comedias, espectadores, actrices y actores, así como el estado físico de algunos teatros de la Ciudad de México" (Castro y Curiel: 28). La circunscripción de su público se corrobora en la posibilidad con que contaban los capitalinos de recibir su ejemplar en el asiento mismo del teatro cada martes por la noche. Con todo, cabe advertir que la tertulia teatral la componen exactamente los mismos personajes que, por un lado, asisten a los salones literarios. De $E l$ Apuntador, Gutiérrez toma tres poemas: “¿Una ilusión!” de Alejandro Arango, "Iturbide" de José María Lafragua (uno de sus fundadores y editores) y "Diez y seis de setiembre" de Andrés Quintana Roo. ${ }^{13}$ A esta última oda se asocia una fe de erratas aparecida algunos números después, pero Gutiérrez omite enmendar los yerros señalados. ${ }^{14}$ Este hecho permite conjeturar que El Apuntador no llegó completo (24 números

tuvo mejor suerte, hasta que su gran amigo Pesado auspició en 1849 la edición de sus Poesías, con un prólogo suyo. Carpio contaba con 58 años"; de Fernando Calderón aparecieron ediciones en 1828, en 1844 y varias póstumamente; Guillermo Prieto, "el poeta más popular del XIX, quien escribía como poseído, solo publicó su primer libro de poemas, Versos inéditos, en 1879, y su Musa Callejera, 1883, es decir, a los 61 y 65 años de su vida" (593-594).

12 El Apuntador. Semanario de teatros, costumbres, literatura y variedades. México: Casimiro del Collado y José María Lafragua, 1841; El Museo Mexicano. O miscelánea pintoresca de amenidades curiosas e instructivas. México: Ignacio Cumplido, 1843-1846; El Recreo de las Familias. México: Ignacio Rodríguez Galván, 1837-1838. Para más datos, cfr. Castro y Curiel 2000.

${ }^{13}$ T. 1, vII, pp. 104-105; t. 1, XVII, lit. s.p., poema pp. 265-269 y t. 1, xv, pp. 228231, respectivamente, todos de 1841.

${ }^{14}$ El Apuntador 1, XIx: 304, columna II. La corrección dice: "En la página 265 en el segundo de los versos franceses, dice: á des autels: léase, a des autels. En el siguiente dice, a ton génie: léase, à ton génie”. 
en total) al compilador, sino solo números dispersos o, incluso, algunas páginas sueltas.

Mismo fenómeno se observa en El Museo Mexicano, publicación ciertamente exitosa y donde se dieron cita los escritores más sobresalientes de la literatura mexicana decimonónica entre los ańos 1843 hasta 1846. El epígrafe que remata la portada constituye, en términos programáticos, todo una declaración de principios: "Miscuit utile dulci" (Horat), "Mezclo lo útil con lo agradable". De esta dilatada serie, la América poética solo recupera algunos poemas de Guillermo Prieto. ${ }^{15}$

El tercer periódico de donde se extraen obras es, como anticipamos, El Recreo de las Familias, suerte de memoria literaria de la Academia de Letrán que sirve a Ignacio Rodríguez Galván para impulsar al grupo (cfr. Campos: 580). De esta revista quincenal se compendian "La sonrisa del pudor" ${ }^{16}$ de Guillermo Prieto - que viene a completar la selección del poeta tomada de El Museo Mexicano_-, "La risa de la beldad" y "El soldado de la libertad" 17 de Fernando Calderón y, el caso más curioso: la traducción que Castillo y Lanzas hiciera de "La oración", poema de Felicia Dorotea Hemans. ${ }^{18}$

Esta última preferencia es llamativa por varios motivos. Gutiérrez toma las composiciones de Castillo y Lanzas directamente del tomo que reúne sus poesías, editado en Filadelfia en $1835 ;{ }^{19}$ teniendo a la mano el conjunto de sus obras, ¿por qué escoger, entonces, una pieza ajena a este volumen? La pregunta se hace todavía más recóndita cuando consideramos que ni siquiera pertenece al mismo Castillo y Lanzas, sino que se trata de una traducción de una poeta lakista. Este poema resulta, incluso, extraño en el plan mismo de El Recreo de las Familias,

15 "La mujer perdida”, en El Museo Mexicano, t. 3 (1844), pp. 88-89; "Una nube”, en El Museo Mexicano, t. 3 (1844), pp. 18-19; “Trova a María”, en El Museo Mexicano, t. 2 (1843), p. 15 y "Brindis", El Museo Mexicano, t. 4 (1844), p. 570.

${ }^{16}$ El Recreo de las Familias, núm. 1 (1 de noviembre de 1837), pp. 28-29.

17 El Recreo de las Familias, núm. 7 (1 de febrero de 1838), p. 269 y El Recreo de las Familias, núm. 11 (1 de abril de 1838), pp. 415-417, respectivamente. Vale la pena apuntar que el "El soldado de la libertad" es la lectura que el poeta y dramaturgo Calderón escoge para presentarse como miembro de la Academia de Letrán (cfr. Campos: 580).

${ }^{18}$ El Recreo de las Familias, núm. 11 (1 de abril 1838), p. 417.

${ }^{19}$ Las poesías antologadas se corresponden con la siguiente paginación: "Mi deseo", p. 36, "Una revolución”, p. 37, "A la señorita Doña... en sus días”, p. 47, "El patriotismo", p. 67, "La victoria de Tamaulipas, canto", p. 120, "La Grecia, Byron”, p. 183. 
cuya intención era nacionalizar el periódico hasta donde fuera posible. El propósito no pudo concretarse en escasos doce números; su editor dice al respecto: "necesitábamos para ello algún tiempo, y este nos faltaba" (El Recreo de las Familias: 474). El intento de dar a conocer obras y biografías de autores mexicanos no cuajó en el primer tomo, pero sí la voluntad de privilegiar la literatura escrita en español:

Las dos revistas echadas a andar por Rodríguez [Año Nuevo y El Recreo de las Familias] acabarían abriendo en ulteriores años grandes puertas y ventanas para los autores de la tertulia crítica. En un momento, cuando la mayoría de los textos de publicaciones periódicas circulantes era abrumadoramente extranjera (podía llegarse a veces a cerca del $100 \%$ ), este par de revistas son las únicas que proponen una múltiple lectura mexicana basada en textos originales de un grupo más o menos regular de autores (Campos: 584).

De hecho, el poema de Hemans es una rara excepción. Gutiérrez, por su parte, reproduce esta obra en detrimento de muchos otros originales de Castillo y Lanzas. Esto nos conduce a dos suposiciones: la primera es que Gutiérrez - tanto sea por falta de ejemplares, tanto por voluntad- no elige lo más representativo de la revista; la segunda, que no solo le interesa concentrar un conjunto de poesías más o menos distintivo de la lira americana, sino también los influjos que de uno u otro modo la permean. Pablo Rocca dilucida esta práctica del siguiente modo:

La literatura americana adapta lo ajeno y se inventa. En esta línea, se explica que la traducción sea un proceso central desde los primeros pasos de la vida cultural y literarias americanas, y que los parnasos incluyan traslaciones de poemas como si fueran obra propia y autóctona (xv).

La ágil noción literaria de Gutiérrez está encaminada en este sentido; pretende "reunir en un cuerpo las obras escogidas de aquellos americanos que como poetas se han distinguido en los tiempos más recientes" (1846: v), pero no solo eso. Conforme a los altos anhelos del publicista, del hombre de letras, la colección sería parcial de no incluir elementos conexos. El "Prospecto" resulta lo suficientemente claro:

Contrayéndonos a nuestro propósito, observamos que, si mucho se ha hablado en América de su literatura poética, si se la ha juzgado, ya en 
bien, ya en mal, y a veces con ingenio y originalidad, ha sido, sin embargo, sin poseer el caudal bastante de noticias y antecedentes necesario para conseguir el acierto en materia tan delicada de crítica. Bajo este otro aspecto consideramos también útil la publicación de nuestra América poética (Gutiérrez 1846: vi. Subrayado nuestro). ${ }^{20}$

Por consiguiente, las "noticias" de los autores antologados se tornan un punto sustancial dentro del proyecto y no un mero ornato o complemento editorial. La relación que Gutiérrez establece entre vida y obra — fecundo axioma de su siglo — es una de sus vetas mejor estudiadas, por lo mismo, no redundaremos en ello. ${ }^{21}$ Lo que interesa aquí resaltar es el vínculo que establece el crítico entre las biografías de los escritores y las revistas que sirven de surtidoras. Así, El Recreo de las Familias presta nuevamente un buen ejemplo.

Las noticias de cada poeta que preceden la selección no guardan una uniformidad en cuanto a amplitud: algunas no superan las dos líneas, mientras que otras aportan escrupulosas semblanzas, juicios críticos y hasta relaciones bibliográficas. La materia parva se debe, en algunos casos, a la juventud de los protagonistas; en otros, a la falta de pormenores, a veces a ambas, como en el caso de Arango: "Solo sabemos de su autor, que es muy joven y nacido en la República Mexicana” (Gutiérrez 1846: 17). Tras lo expuesto hasta aquí, no sorprende que las noticias de los escritores mexicanos sean breves, sin datos precisos y casi siempre demoradas en anécdotas tangenciales. ${ }^{22}$ En algunos pasajes se opta, directamente, por aplazar el relato y dejarlo pendiente:

20 El valor de la traducción en el cuadro poético americano se constata también en el siguiente pasaje del prólogo, justamente al describir el estado de la poesía actual, es decir, la que integra el volumen: "[Pasada la revolución política...] Los poetas pudieron pensar ya en sí mismos e interesar con sus dolores o con sus dichas personales. [...] Aquellos mismos que antes cantaron a los héroes, cantan a las Rosas, o vierten a la lengua materna las descripciones de Delille o los pensamientos de Pope. Pesado traduce a David y se inspira en los sagrados libros. Varela (infatigable atleta poético) traduce a Horacio y muere con la Eneida en la mano esforzándose por continuar la versión de este poema" (Gutiérrez 1846: VIII).

21 Cfr. Amante 2003, Croce 1999, Rosa 1987 y, de modo directo, Gutiérrez 1957.

22 Con verdadero arte de compilador, Gutiérrez extrae y aprovecha hasta las citas más breves que localiza acerca de tal o cual autor. Casi todos estos fragmentos provienen de México considerado como nación independiente y libre... de Tadeo Ortiz (Burdeos: Imprenta de Carlos Lawalle Sobrino, 1832), de las Obras sueltas de José 
Las poesías líricas de Calderón, se han impreso en México en estos últimos meses; pero no las hemos obtenido todavía: las publicaremos en el "apéndice" que la naturaleza de nuestra colección exige indispensablemente y allí daremos las noticias biográficas de que carecemos en este momento (126).

La ignorancia que evidencia la América poética respecto de los literatos mexicanos corrobora la falta de proximidad entre zonas tan distantes del orbe hispanoamericano. Al mismo tiempo comprueba el vacío biográfico que en este punto muestran las revistas mexicanas o, más exactamente, El Recreo de las Familias, publicación de mayor peso entre las tres que hemos revisado.

Cerremos este recorrido con un último ejemplo. Una de las mejores introducciones que ostenta la América poética es la que dedica a José María Heredia. En ella se hace un pormenorizado informe de sus principales sucesos biográficos, sin omitir los viajes, la formación, empleos y acciones políticas. En opuesta dirección a la costumbre tan arraigada por estos años de omitir las fuentes y sus autores, ${ }^{23}$ este escrito deja constancia de la procedencia de las noticias:

Don J. M. Heredia vivía en México el año de 1838, pues es esta la época en que se publicaba allí el periódico literario de donde tomamos estas rápidas noticias. Su autor refiriéndose a ellas y al retrato que las acompaña, dice: "El Sr. Heredia recibirá ambas cosas como un sincero homenaje del respeto y admiración que nos inspira” (285).

Si bien en esta ocasión no se menciona el nombre del periódico, se refiere - sin dudas - a El Recreo de las Familias. En su número 7 (1 de febrero de 1838, pp. 241-245), en la sección principal, aparece un amplio estudio dedicado al poeta antillano firmado por Eulalio Ortega, el cual incluye "la más antigua biografía de Heredia, escrita un año antes de su muerte, con datos proporcionados por Heredia, de fijo"

María Luis Mora (París: Librería de Rosa, 1837) y de la "Advertencia preliminar" de la Colección de poesias mejicanas.

${ }^{23} \mathrm{La}$ mejor muestra de estos plagios y préstamos inciertos la ofrecen las fabulosas biografías de sor Juana que circularon a lo largo de todo el siglo xIx. Cfr. el estudio de Antonio Alatorre y Martha Lilia Tenorio, "Una enfermedad contagiosa: los fantaseos sobre Sor Juana” (Nueva Revista de Filología Hispánica XLVI, 1 [1998]: 105-121). 
(Toussaint: 93), la reproducción de una carta-crítica de autor español $y$, como corolario, un retrato en técnica litográfica del mismo poeta, único de "factura enteramente mexicana" (Ruiz Castańeda: XLI) en toda la revista.

Si bien Gutiérrez modifica el orden del texto e interviene en la composición del mismo, las variantes que se registran son de orden sintáctico, sin adicionar información complementaria, a excepción del relevo bibliográfico de las obras del cubano. Tan difícil es el tránsito de noticias de una parte a otra del continente, que aun pasados más de cinco años, el editor no puede precisar la fecha exacta de la muerte de Heredia: se tienen "motivos para creer que su muerte acaeció a fines del año 1839", pero no certezas.

Lo curioso del caso es que la América poética saca el máximo rendimiento de estas noticias, las únicas que se publican a lo largo de los doce números de El Recreo sobre un escritor hispanoamericano. Esta circunstancia nos enfrenta a otra cuestión: la falta de tratamiento de autores locales en las publicaciones mexicanas. La nacionalización de la revista — explica María del Carmen Ruiz Castañeda — "tropezó con la crónica escasez de originales, entre otros motivos porque los literatos estaban muy ocupados redactando periódicos políticos y siempre hubo necesidad de recurrir a la copia y traducción de materiales extranjeros" (xLv). La pregunta queda abierta: ¿'habría en la América poética más poemas o mejores noticias de autores mexicanos de haber triunfado la pretendida nacionalización? Difícil es determinarlo, aunque no sobra pensar la distintiva participación de este bloque poniendo atención no solo a las causas exógenas, sino también a las emanadas del propio sistema literario mexicano.

\section{Algunas Noticias SObre LA ReCePCión MEXiCANA DE LA AMÉRICA POÉTICA}

1849 es el año clave para la recepción mexicana de la América poética. Por dos razones: en primer término, porque durante la segunda mitad del año la prensa revela una entusiasta acogida comercial a la colección sudamericana; en segundo, porque — al menos hasta donde pude rastrear- esta solo se registra en este período, sin volver a nombrarse en los años que siguen. Dejo de lado la última aserción, por cuanto es sus- 
ceptible de futuras rectificaciones. Sin embargo tiene sentido, aunque sea brevemente, enlistar las apariciones en la prensa local.

La primera noticia está fechada el 21 de junio de 1849, en el diario El Siglo Diez y Nueve de la ciudad de México. Es un anuncio que, con aviso especial, se dedica a la promoción de la obra en exclusiva:

AмÉRICA PoÉTICA. Han llegado algunos ejemplares de esta obra interesantísima, que contiene producciones escogidas de los poetas más notables del continente americano. Este libro es tanto más apreciable para los mexicanos, cuanto que se ha dado en él lugar a las composiciones de los señores Arango, Carpio, Calderón, Pesado, Prieto, Tagle y algunos otros que han ilustrado nuestra literatura.

La obra consta de un tomo grueso en $4^{\circ}$ mayor, encuadernado a la holandesa; y se expende al moderado precio de 7 pesos, en la librería del Siglo XIX, situada en la primera calle de Plateros número $1 .{ }^{24}$

Resulta interesante constatar la confianza que el librero del Siglo XIX confiere a la obra, seguro de que merece la atención del lector y el favor de la compra: en caso contrario no se habría tomado la molestia de anunciar con tanta solicitud la llegada de los ejemplares a la prestigiosa casa comercial. Es, por otra parte, notorio que escoja distinguir a los escritores mexicanos y no a los vates del subcontinente que sobresalen y que ya son seguros moradores del Parnaso americano (como Echeverría, Olmedo, Fernández Madrid o Bello), los que pudieran despertar —en su calidad de inhallables en los anaqueles de la capital—el interés del público.

Poco después, el 19 de julio (y reimpreso en al menos siete números siguientes), se publica en la última página del mismo diario un anuncio donde de nuevo figura la América poética, esta vez entre las novedades de la mencionada librería. La acompañan ahora La guerra de las mujeres (1845) de Alejandro Dumas, Picciola (1836) de X. B. Saintine, Historia de los girondinos (1847) de Alphonse de Lamartine, Los viajes de Gulliver (1726) de Jonathan Swift, Robinson Crusoe (1719) de Daniel

${ }^{24}$ Sin firma, "América poética" (anuncio), en El Siglo Diez y Nueve (México), t. I, núm. 172 (21 de junio de 1849), p. 688, columna 4 (vuelto a imprimir los días 23, 24 y 30 de junio). 
Defoe y La risa: enciclopedia de extravagancias (1843-1844). ${ }^{25}$ De este selecto séquito de primicias, la antología de Gutiérrez resulta diversa, puesto que su naturaleza es distinta de las demás: se trata de una "colección lírica" mientras el resto lo conforman obras en prosa, especialmente adscriptas al género "novela"; con la enciclopedia de extravagancias son las únicas escritas en español (la gran mayoría son traducciones del francés y del inglés); y — peculiaridad que destaca- es la única de procedencia americana. Cabe decir que una lista no muy heterogénea se publica durante los meses de noviembre y diciembre, ahora con algunas incorporaciones mexicanas y en el contexto de la Feria de San Juan de los Lagos. ${ }^{26}$

Sin embargo, la nota más llamativa se da a conocer el 6 de septiembre de 1849. El texto sin firma lleva por título "Academia de Letrán"27 y en él se narran los sucesos en torno a la elección del himno nacional. En 1848, el pianista austríaco Henri Herz ofrece componer un himno, sorprendido de que la nación no contara con uno. La Academia de Letrán, nacida en el Colegio de San Juan de Letrán a instancias de José María Lacunza en 1836, no tenía por ese entonces la regularidad y cohesión de sus mejores días; sin embargo, asume como propia la propuesta, desempeña el encargo y convoca a un concurso para elegir la letra del canto nacional. El 3 de septiembre se reúnen los más prestigiosos miembros del grupo - entre ellos Lacunza, Prieto, Quintana Roo, Carpio, Pesado, Lafragua y Arango- para conocer el dictamen sobre las dieciséis obras presentadas. Se leen las composiciones y en seguida el juicio de la comisión calificadora: el ganador es Andrés Davis Bradburn, hijo de uno de los oficiales ingleses venidos al país en la expedición de Francisco Javier Mina, cuyo poema resulta "preferible para cantarse por ahora", "aunque el mérito literario de la segunda sea igual, si no superior a aquella". Esta segunda letra pertenece a Félix María Escalante. Y aquí lo que interesa:

25 Sin firma, "En la librería del Siglo XIX" (anuncio), en El Siglo Diez y Nueve (México), t. II, núm. 200 (19 de julio de 1849), p. 79, columna 3 (vuelto a imprimir los días 20 y 22 de julio, 7, 9, 27 y 28 de septiembre y 7 de octubre).

26 Sin firma, "San Juan de los Lagos. Burmand y Compañía" (anuncio), en El Siglo Diez y Nueve (México), t. II, núm. 320 (16 de noviembre de 1849), p. 606, columna 4 (vuelto a imprimir los días 18, 19 y 28 de noviembre y 1 y 2 de diciembre).

${ }^{27}$ Sin firma, "Academia de Letrán”, en El Siglo Diez y Nueve (México), t. II, núm. 249 (6 de septiembre de 1849), p. 272, columnas 1 y 2. 
Los censores, para dar a los señores Davis y Escalante una prueba del aprecio que les merecen, los premiaron a uno con las obras de Martínez de la Rosa, y a otro con la América poética. Ambos jóvenes estaban poseídos de la más viva emoción, de que participaban todos los concurrentes; y la juventud estudiosa de Letrán se mostraba regocijada, al ver que un compañero suyo se había hecho acreedor a una distinción tan honorífica y envidiable.

El que sea la América poética el galardón escogido para premiar a Escalante persuade con suficiente argumento de la consideración y estima con que los lateranenses reputaron la colección, ligada —a partir de esta pequeńa anécdota - a la historia de la lírica "patriótica".

\section{A MODO DE CONCLUSIÓN}

La distancia, lo accidentado del trato, la falta de vínculos, en fin, el alejamiento geográfico e histórico que separa a México de las naciones sudamericanas tornan poco enérgicas las relaciones entre los intelectuales coetáneos. Las revistas, por su parte, llegan de forma fragmentaria y casi siempre con una pobre participación vernácula. Pese a esto, la América poética ni desmerece el lugar y preponderancia asignado a México ni relega los materiales provenientes de las publicaciones periódicas. Todo lo contrario.

Gutiérrez dispone de algunos libros, entre ellos la Colección de poesías mejicanas de Mora y, sin embargo, concede a las revistas literarias una activa participación. Muchas pueden ser las razones de esta preferencia: dejemos apuntadas solo dos.

La generación que sostiene ideológicamente el plan de la antología — la del 37 - tiene respecto del diarismo en general una firme confianza, tanto por la democratización que garantiza su accionar, como por la incidencia que asegura en la opinión pública. Aun así, el rasgo que mejor se ajusta al propósito de la antología es su actualidad, su espíritu novedoso y sensible a la temperatura de los tiempos que corren. La América poética se quiere contemporánea, se precia de reunir en sus páginas poetas "vivos, o muy recientemente muertos, cargados de promesas, en la flor de la juventud" (viII): de esto a que su mejor cantera sean las revistas literarias del día media un solo paso. Además, este tipo 
de publicaciones hacen ostensibles las tendencias literarias en boga, la adhesión o rechazo que suscitan y las preferencias poéticas de los lectores, aspectos en absoluto desdeñados por el compilador.

De hecho la América poética comparte con estos periódicos especializados un mismo receptor, una misma nómina de suscriptores que gustan de la poesía lírica, un mismo "público ilustrado e igualmente sensible a la razón del filósofo y al arte del poeta romántico" (Batticuore: 113). Estas revistas tienen en general buenas intenciones, se conciben como órganos publicitarios, divulgadores de una literatura que se desea popularizar; "cuando en realidad... para el verdadero público —ese inmenso público formado entre ambos extremos de la escala intelectual-, han vivido de incógnito". ${ }^{28}$ Por su parte, Gutiérrez suscribe su prólogo con retórica entusiasta aunque particularizada: "a los poetas americanos, sus ardientes admiradores". Una y otra fórmula se traduce en términos efectivos al mismo selecto público.

\section{BibliografíA}

Amante, Adriana. "La crítica como proyecto. Juan María Gutiérrez", en Noé Jitrik (dir. gral.), Julio Schvartzman (dir. del volumen). Historia crítica de la literatura argentina. Vol. 2. Buenos Aires: Emecé Editores, 2003: 161190.

Auza, Néstor Tomás. “América Poética. Primera antología de la lírica americana”, en Cuadernos Hispanoamericanos, 500 (1992): 141-151.

Batticuore, Graciela. "La lectura, los escritores y el público. 1830-1850", en Graciela Batticuore, Klaus Gallo y Jorge Myers (comps.). Resonancias románticas: ensayos sobre historia de la cultura argentina 1820-1890. Buenos Aires: Eudeba, 2005: 101-117.

Campos, Marco Antonio, "La Academia de Letrán”, en Literatura Mexicana (México), vol. VIII, núm. 2 (1997), pp. 569-596.

Campra, Rosalba. "Las antologías hispanoamericanas del siglo xix. Proyecto literario y proyecto político", en Casa de las Américas, XXVII, 162 (mayojunio de 1987): 37-46.

Castro, Miguel Ángel y Guadalupe Curiel, coord. y asesoría. Publicaciones periódicas mexicanas del siglo XIX: 1822-1855. Fondo Antiguo de la Heme-

${ }^{28}$ Citado por Ruiz Castañeda: LVII-LVIII. El fragmento corresponde a Ángel González García y Francisco Calvo Serraller. "Estudio preliminar”, en El Artista. Ed. facsímil. T. I. Madrid: Turner, 1981: xxI. 
roteca Nacional y Fondo Reservado de la Biblioteca Nacional de México (Colección Lafragua). Asesoría técnica de Gabriela Lorena Gutiérrez Schott y Ana María Romero Valle; colaboradores: Martha Celis de la Cruz et al. México: Universidad Nacional Autónoma de México, 2000.

Croce, Marcela. "Fundación y resonancias de la crítica sociológica argentina: Juan María Gutiérrez”, en Nicolás Rosa (ed.). Políticas de la crítica: historia de la crítica literaria en la Argentina. Buenos Aires: Editorial Biblos, 1999: 33-40.

El RECREO DE LAS FAMILIAS. Ed. facsimilar y est. preliminar de María del Carmen Ruiz Castañeda; índices elaborados por Sergio Márquez Acevedo bajo la coord. de María del Carmen Ruiz Castañeda. Facsim. de: Megico: Libreria de Galvan, 1838. México: Universidad Nacional Autónoma de México, 1995.

Gutiérrez, Juan María. América poética. Colección escojida de composiciones en verso, escritas por americanos en el presente siglo. Parte Lírica. Valparaíso: Imprenta del Mercurio, 1846.

Gutiérrez, Juan María. Escritores coloniales americanos. Ed., pról. y notas de Gregorio Weinberg. Buenos Aires: Editorial Raigal, 1957.

Gutiérrez, Juan María. Epistolario. T. I. Ed. a cargo de R. J. Moglia y M. O. García. Buenos Aires: Biblioteca del Congreso de la Nación, 1979.

Gutiérrez, Juan María. Epistolario. T. II. Ed. a cargo de R. J. Moglia y M. O. García. Buenos Aires: Biblioteca del Congreso de la Nación, 1981.

Guzmán Moncada, Carlos. De la selva al jardín. Antologías poéticas hispanoamericanas del siglo XIX. México: Universidad Nacional Autónoma de México, 2000 .

Henríquez Ureña, Pedro. "El descontento y la promesa”, en Ensayos. Ed. crítica coordinada por José Luis Abellán y Ana María Barrenechea. Buenos Aires: Editorial Sudamericana (Archivos), 2000: 273-286 [1926].

Lamas, Andrés, Juan María Gutiérrez, José Rivera Indarte y Teodoro Vilardebó (comp.). Colección de poetas del Río de la Plata. Ed., pról. y notas de Pablo Rocca, trascripción paleográfica del texto Valentina Lorenzelli. Montevideo: Ministerio de Educación y Cultura, 2011 (Colección de Clásicos Uruguayos, Biblioteca Artigas, 189).

Mora, José María Luis. Colección de poesías mejïcanas. París: Librería de Rosa, 1836.

Reyes, Alfonso. "Teoría de la antología”, en La experiencia literaria. $3^{a}$ ed. Buenos Aires: Losada, 1969: 129-133.

Rocca, Pablo. "Prólogo", en Andrés Lamas, Juan María Gutiérrez, José Rivera Indarte y Teodoro Vilardebó (comp.). Colección de poetas del Río de la Plata..., 2011: VII-LXX. 
Rodríguez Martín, Bárbara. Juan María Gutiérrezy su contribución periodística (1833-1852) a la crítica cultural hispanoamericana. Tesis de doctorado, 2 tomos. La Laguna: Universidad de la Laguna, 2005/6. En línea, disponible en: <ftp://tesis.bbtk.ull.es/ccssyhum/cs215.pdf >.

Rojas, Ricardo. La literatura argentina. Ensayo filosófico sobre la evolución de la cultura en el Plata. Vol. III: Los proscriptos. Buenos Aires: Coni hermanos, 1920.

Rosa, Nicolás. "J. M. Gutiérrez: crítica e historia”, en Los fulgores del simulacro. Santa Fe: Universidad Nacional del Litoral, 1987: 56-77.

Ruiz Castañeda, María del Carmen. "Estudio preliminar”, en El Recreo de las Familias..., 1995: XI-LVIII.

Sarmiento, Domingo Faustino. Obras. T. II: Artículos críticos i literarios 18421853. Santiago de Chile: Imprenta Gutenberg, 1885.

Serrano-Ortega, José Antonio y Josefina Zoraida Vázquez. "El nuevo orden, 1821-1848”, en Erik Velásquez García, et al. Nueva historia general de México. México: El Colegio de México, 2010: 397-442.

Stuven, Ana María. "El exilio de la intelectualidad argentina: polémica y construcción de la esfera pública chilena (1840-1850)", en Carlos Altamirano (dir.). Historia de los intelectuales en América Latina. T. I: La ciudad letrada, de la conquista al modernismo. Editor del vol.: Jorge Myers. Buenos Aires-Madrid: Katz, 2008: 412-440.

SuÁrez de la Torre, Laura. "La producción de libros, revistas, periódicos y folletos en el siglo xix", en Belem Clak de Lara y Elisa Speckman Guerra (eds.). La República de las Letras. Asomos a la cultura escrita del México decimonónico. Vol. II: Publicaciones periódicas y otros impresos. México: Universidad Nacional Autónoma de México, 2005 (Al Siglo XIX. Ida y Regreso): 9-25.

Tola de Habich, Fernando. "Diálogo sobre los Año Nuevo y la Academia de Letrán” (estudio preliminar), en El Año Nuevo de 1837. T. I. Edición facsimilar. México: Universidad Nacional Autónoma de México, 1996: IX-CXXXV.

Toussaint, Manuel. Bibliografía mexicana de Heredia. México: Secretaría de Relaciones Exteriores, 1953.

FECHA DE RECEPCIÓN: 14 de diciembre de 2012

FECHA DE ACEPTACIÓN: 21 de marzo de 2013 